\title{
Impact of 100-MW-scale PV plants with synchronous power controllers on power system stability in northern Chile
}

\author{
Daniel Remon ${ }^{1, *}$, Claudio A. Cañizares ${ }^{2}$, Pedro Rodriguez ${ }^{3,1}$ \\ ${ }^{1}$ Department of Electrical Engineering, Technical University of Catalonia, 08222 Barcelona, Spain \\ ${ }^{2}$ Department of Electrical and Computer Engineering, University of Waterloo, Waterloo, ON N2L 3G5 Canada \\ ${ }^{3}$ Department of Engineering, Loyola University Andalusia, 41014 Seville, Spain \\ *daniel.remon@estudiant.upc.edu
}

\begin{abstract}
The impact that renewable energy sources interfaced by power electronics have on power systems becomes more important as their share in the generation mix increases, thus requiring detailed analyses that take into account their dynamics and controllers. In this paper, the impact of photovoltaic (PV) power plants on the power system of northern Chile is analysed. The studied plants employ a controller that allows power converters to interact with the grid like virtual synchronous generators, and their model includes the dynamics of the plant and converter controllers, as well as the dc and PV system. The presented analysis, which comprises modal analysis and time-domain simulations of large disturbances, evaluates the impact of these plants with respect to PV plants based on a conventional converter controller. Tests and validations of the proposed models and controllers are carried out for an actual PV plant connected to the power system of northern Chile, and for a higher PV penetration case. The results show the ability of PV plants formed by virtually synchronous power converters to limit frequency excursions induced by large power imbalances, and to mitigate power oscillations of the synchronous machines in the system.
\end{abstract}

\section{Introduction}

The fraction of total power generation obtained from renewable energy sources has increased as associated technologies have matured and become more competitive. This trend is expected to continue in the coming years, with some sources like wind and solar energy reaching penetration levels of around 30\% in some power systems [1-4]. These kinds of power plants, formed by wind generators or solar PV systems, have an impact on the grid, not only due to the special characteristics of the resource, but also because of the technology employed to deliver the energy into the power network, which in many cases is based on power electronics. Contrary to synchronous generators, the dynamics of power electronics converters are fast (normally in the range of a few grid cycles), and their interaction with the grid is mainly determined by their controllers, which are often designed to extract maximum power from the source, without taking into account the interaction with the power system. As the share of these generators in the energy mix increases, with many distributed generators connected to distribution networks, and also large-scale converter-based power plants being connected to transmission grids, it becomes necessary to analyse and mitigate the impact of these systems, designing 
adequate control strategies and possible system upgrades.

Several works have studied the aforementioned issues. The integration of distributed generators is reviewed in [5], and control strategies for active distribution networks with a large penetration of these generators are evaluated in [6]. Furthermore, the impact of solar photovoltaic units on real distribution systems has also been analysed [7,8]. At the transmission level, the analyses focus in many cases on theoretical power plants and test power systems. For instance, [9] and [10] study the transient stability of a 9-bus system under the presence of wind and PV sources, respectively. A few papers consider the impact of renewables on the operations and economics of real systems; for example, wind curtailment in Spain is studied in [11]; the expansion of the interconnection between Spain and France to integrate intermittent generation is addressed in [12]; reactive power reserves in Denmark are analysed in [13]; load-following, regulation, and associated markets in California are discussed in [14]; and generation imbalances in Finland are considered in [15]. Regarding the impact on the stability of real power grids, the impact of wind generators on power system dynamics in Spain is discussed in [16]; the impact of PV, considering different paths for large-scale integration, is analysed in [17] for the Ontario power system; the impact of renewables on regional systems is studied in [18], where the effects of renewable generation on the inertia of the European interconnected system are calculated; and in [19], the impact of PV on small-disturbance and transient stability of the western interconnection in North America is discussed. Finally, weaker, smaller-scale systems more prone to instability problems under the presence of wind generators are discussed in [20], [21], and [22].

In all the previously mentioned works, renewable generators employ conventional controllers that meet grid codes, but are not specifically designed to interact harmoniously with the grid. However, there are proposals of renewable generator controllers that contribute to the stabilization of power system. Thus, [23] presents a robust controller for large PV plants that performs power oscillation damping through the modulation of reactive power, and [24] proposes a strategy to improve frequency stability through voltage control under the presence of voltage-dependent loads. Another approach is to reproduce some features of synchronous generators. Thus, the provision of synthetic inertia is studied in [25], and this concept is extended to the emulation of a synchronous machine, which leads to the so-called virtual synchronous generators [26]. The effect of these types of controllers has been normally analysed only in small test systems, considering one converter connected to the main grid or a small microgrid [27-32]. However, their impact on bulk power systems, which may be subject to phenomena and interactions that are not present in smaller systems, has not been addressed in detail. A first approach is presented in [33], where a 12-bus test power system is studied 
and PV is modelled only as an active power limitation.

In this paper, the impact on an actual transmission power system of large-scale power plants formed by virtually synchronous power converters is analysed. The plant model is based on a $100 \mathrm{MW}$ PV power plant connected to the power system of northern Chile, and considers the dynamics introduced by the PV plant and converter controllers using a dynamic equivalent model for stability studies. Each converter in this plant can behave as a virtual synchronous generator through a Synchronous Power Controller (SPC) [34,35]. In order to assess the impact of this controller, the results are compared to those obtained with a conventional converter controller [36]. Small- and large-disturbance stability studies are carried out for the real power system of northern Chile with PV generation. The main contributions of the paper are the following:

- Inclusion of the converter dc side and PV system models in the equivalent model of the PV plant.

- Modelling and analysis of the impact of the real PV plant connected to the power system of northern Chile, considering its capability to use the SPC.

\section{PV Power Plants with Synchronous Power Controllers}

The PV power plant considered in this paper is based on a real $100 \mathrm{MW}$ power plant connected to the power system of northern Chile, which is formed by 100 power converters with a rated power of $1 \mathrm{MW}$ each, and connected to the $50 \mathrm{~Hz}, 220 \mathrm{kV}$ grid. Each of the converters can be controlled by an SPC [34], which embeds certain features of synchronous generators in the converter dynamics, so that the plant has the ability to interact synchronously with the power system.

For the system analyses presented in this paper, the power plant is represented by an equivalent singleconverter, fundamental-frequency, balanced, aggregated model that considers two control layers, as described in detail in [37]. The upper layer is the central plant control, and the lower layer is the equivalent converter controller, which inherits the characteristics of the SPC controlling each unit. In addition, the model includes the dynamics of an equivalent dc link and PV field.

\subsection{Central Plant Controller}

The central plant controller sends active and reactive power references to the equivalent converter controller, together with the measurement of the frequency at the point of common coupling (PCC) of the power plant, to be used only for frequency regulation purposes. On the one hand, a constant active power reference is set at the plant level, considering a $10 \%$ reserve so that the plant can modify its output to respond to certain 
grid events. The active power reference received at the converter level is modified locally, taking into account the frequency measurement at the PCC. On the other hand, the plant controls the voltage at the PCC with a proportional controller that generates the reactive power reference for the converter level.

\subsection{Converter Controller}

The core of the converter controller is the SPC, which emulates the electromotive force (EMF) of a virtual synchronous generator behind a virtual admittance, and is formed by three main blocks. Thus, a reactive power controller generates the amplitude of the voltage source representing the virtual EMF, taking into account the reactive power error, and using a proportional-integral controller. On the other hand, the active power controller synthesizes a swing equation with damping. With this equation, the active power error results in a virtual rotor speed that eventually defines the phase-angle of the virtual EMF; furthermore, this loop allows the converter to be naturally synchronized with the grid, thus not requiring an ancillary Phase-Locked Loop (PLL). With the outputs of these two blocks, which fully define the virtual EMF, the electrical characteristic controller determines the current reference for the power converter. This current corresponds to the one that would flow through the virtual admittance, resulting from the voltage difference between the internal virtual EMF and the voltage at the converter point of connection.

The converter controller may include frequency and voltage droops that respectively modify the active and reactive power references received from the central controller. Figure 1 represents the complete converter control diagram for stability analysis. The dynamic response of the inner current control loop is represented by means of a low-pass filter with a typical 1/4-cycle time constant applied to the current reference calculated by the SPC.

The impact of a PV plant consisting of multiple virtually synchronous power converters can be assessed with respect to the impact of a similar plant employing power converters with a conventional vector-orientedcontrol strategy, based on instantaneous power theory (IPT) [36]. When the latter is enabled, the current reference is directly obtained from the reference apparent power and terminal voltage phasors:

$$
\underline{I}^{r e f}=\left(\frac{P^{r e f}+j Q^{r e f}}{\underline{V}}\right)^{*}
$$

Like in the case of the SPC, this conventional strategy considers the frequency and voltage droops, and the delay of the current control loop. However, when the conventional controller is employed, the delay of the current loop also includes the effect of the PLL that this controller requires to be synchronized with the grid. 


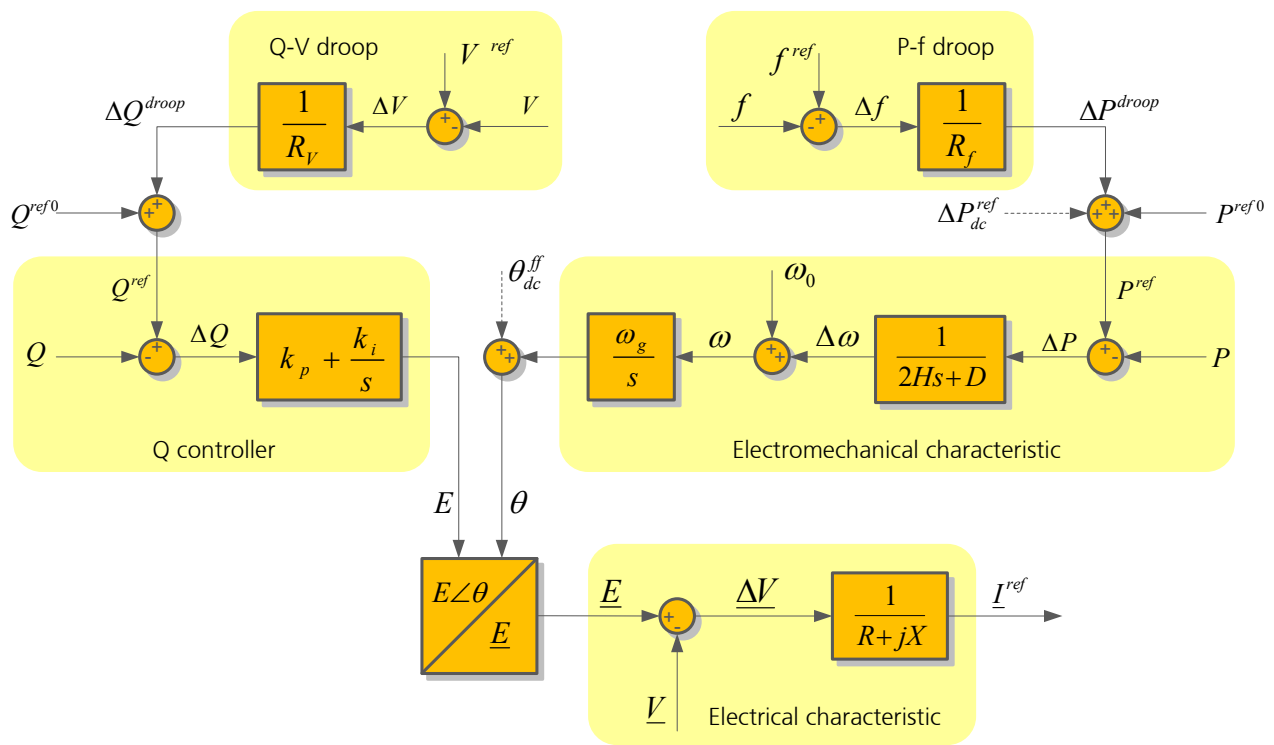

Fig. 1. Model of the SPC of the PV power plant.

\subsection{Side and PV Model}

In order to take into account the limitations imposed by the solar resource when assessing the possible impact of the PV plant, the model proposed in this work includes the dynamics of the dc side and the PV system characteristics. Thus, the power converter dc link is modelled as an ideal capacitor whose voltage is subject to the converter active power balance. The current charging the capacitor is obtained from the difference between the power generated by the PV system and the active power injected by the converter into the grid, dividing both terms by the dc voltage.

The power generated by the PV system is calculated with a simple two-diode model [38], where the current generated by the PV system is a function of solar irradiance, temperature, and dc voltage. The dynamics of the solar irradiance and the temperature are significantly slower than those of the grid events considered in this analysis, and thus these magnitudes are considered as constant parameters. Therefore, the maximum power point tracking algorithm is not included in the model used in this paper.

Since the converter controller of Fig. 1 does not consider the dc side, an additional dc voltage controller, shown in Fig. 2, is implemented here. This controller has a wide deadband that corresponds to the stable part of the PV array characteristics, i.e., the range of voltages between the maximum power point and the opencircuit voltages. However, when one of these limits is reached, a proportional-integral controller is activated, modifying the active power reference of the converter controller, so that the voltage is brought back within its normal range of operation. In order to avoid the delay introduced by the SPC electromechanical controller in this fast control action, a feed-forward branch is included. The signals generated by the dc voltage controller 
modify the active power reference and the angle state of the SPC as indicated in Fig. 1 with dashed lines.

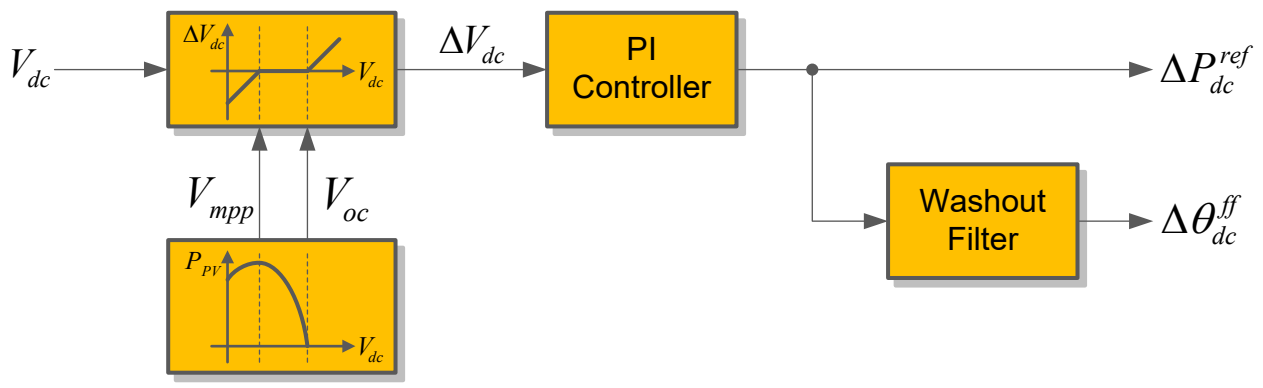

Fig. 2. Diagram of the dc voltage controller of the PV power plant.

\subsection{Plant Model}

The equivalent plant model is implemented in DIgSILENT PowerFactory ${ }^{\circledR}$ to carry out several types of analyses including power flow, modal analysis, and time-domain simulation. The model consists of a static generator element, which models the equivalent converter and filter; an internal busbar where this static generator is connected; and a general impedance connecting this bus to a grid node, which represents the equivalent plant impedance. Furthermore, it includes user-defined functions that describe the control structure of the plant and its controllers by means of a set of differential-algebraic equations. The employed equivalent single-converter model allows speeding up the calculations involved in the different analyses and simulations without losing accuracy, as demonstrated in [37], where several equivalent models with different degrees of aggregation are compared.

\section{Studied System}

The power system of northern Chile is a $50 \mathrm{~Hz}$ system with an average demand around 2,000 MW [39]. Industrial loads associated with mining constitute the main part of this demand, with relatively small hourly variations. The generation mix is mainly coal, natural gas, and diesel, although a significant number of PV plants are being installed or are planned to be connected in the near future.

A schematic view of the central part of the system is illustrated in Fig. 3, based on a detailed description available in [40]. The main trunk of the system stretches from Tarapacá to Atacama, containing large power plants connected electrically close to the Crucero Bus. One of the studied PV plants is a $100 \mathrm{MW}$ PV power plant currently being constructed, connected to one circuit of the Encuentro-Sierra Gorda line, as depicted in Fig. 3. This plant is designed to use power converters that can operate with the SPC option. 


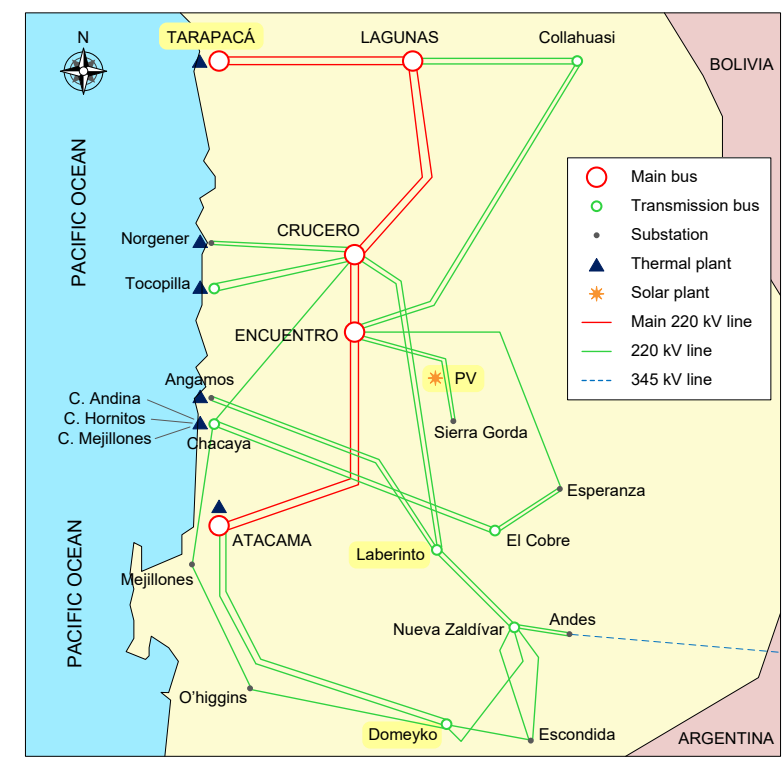

Fig. 3. Simplified diagram of the power system of northern Chile [40].

The study here takes into account the power system model in DIgSILENT PowerFactory ${ }^{\circledR}$ published by the system operator [41]. A low demand operation scenario is considered, which corresponds to maximum existing PV power generation and no interconnection with Argentina. This operation scenario is modified to add the planned $100 \mathrm{MW}$ PV plant at the same demand level, disconnecting a synchronous generator. Furthermore, in order to evaluate the impact of PV plants with SPCs for an increased penetration level, the rated power of the planned PV plant is increased to $200 \mathrm{MW}$, and three more $200 \mathrm{MW}$ PV plants are added to the system, summing up a total of $800 \mathrm{MW}$, and increasing the total demand accordingly. The additional PV plants are located at future solar PV sites; thus, one of these plants is connected at Parinacota Bus north of Tarapacá, whereas the other two plants are connected at Domeyko and Laberinto Buses.

In both scenarios, the solar radiation and temperature are such that the PV plants are able to generate a maximum of 1.015 p.u. active power at 0.64 p.u. dc voltage, and their open-circuit dc voltage is 0.79 p.u., considering a plant per-unit system. Additionally, the initial operating point of the PV plants considers a $10 \%$ active power reserve margin, so that they can contribute to frequency control and stability, and both IPT and SPC controllers are considered.

The active power generation for the main generators in the modified scenarios is slightly modified with respect to the June 2015 low demand data in [41], as shown in Table 1. In both $100 \mathrm{MW}$ and $800 \mathrm{MW}$ PV scenarios, it is assumed that the PV plant replaces unit U14 at Tocopilla, whereas unit U16, also at Tocopilla, increases its active power injection to $211 \mathrm{MW}$. On the other hand, the setpoint of unit U15 is modified in each scenario; in the $100 \mathrm{MW}$ PV case, U15 operates at its technical minimum of $75 \mathrm{MW}$, and in the $800 \mathrm{MW}$ 
Table 1 Active Power Injections (p.u.) of Main Generators in Northern Chile for Different Penetration Scenarios

\begin{tabular}{|c||c|c|c|}
\hline Generator & No PV & 100 MW PV & 800 MW PV \\
\hline \hline ANG1 & 2.05 & 2.27 & 2.23 \\
ANG2 & 2.63 & 2.63 & 2.63 \\
U16 & 1.70 & 2.11 & 2.11 \\
CTH & 1.58 & 1.58 & 1.58 \\
CTM2 & 1.54 & 1.54 & 1.54 \\
CTM1 & 1.49 & 1.49 & 1.49 \\
CTTAR & 1.40 & 1.40 & 1.40 \\
NTO1 & 1.35 & 1.35 & 1.35 \\
NTO2 & 1.35 & 1.35 & 1.35 \\
CTA & 1.30 & 1.30 & 1.30 \\
U14 & 1.22 & - & - \\
U15 & 1.16 & 0.75 & 1.30 \\
TG1A & 0.95 & 0.95 & 0.95 \\
TV1C & 0.60 & 0.60 & 0.60 \\
PV1 & - & 0.90 & 1.80 \\
PV2 & - & - & 1.80 \\
PV3 & - & - & 1.80 \\
PV4 & - & - & 1.80 \\
\hline
\end{tabular}

PV case, it generates $130 \mathrm{MW}$, close to its maximum. The load increase that takes place in the $800 \mathrm{MW}$ scenario is compensated by both the increase of power generated by U15 and the additional PV generation. It is worth noting that, although this high PV penetration scenario brings benefits to the power system economics and sustainability, the resulting dispatch causes a reduction of the ratio of power generated by conventional synchronous machines, and thus the total system inertia decreases.

Taking into account the characteristic of the generators connected to the power system of northern Chile, described in [41], the PV plants are assumed to contribute to frequency regulation with a 5\% droop, and the SPC considers an inertia constant of $5 \mathrm{~s}$. Furthermore, a damping coefficient $D$ such that the damping ratio of the PV plant active power loop is 0.7 , and a virtual reactance equal to 0.3 p.u. are chosen, so that the plant response is sufficiently damped, closely interacting with the grid. 


\section{Results}

The impact of these PV plants on the system, depending on the total penetration and their control, is evaluated by studying the stability of the system with DIgSILENT PowerFactory ${ }^{\circledR}$ for the three disturbances discussed next.

\subsection{Line Contingency}

The event is a short circuit on Circuit 2 of the Crucero-Encuentro line, that starts at $t=1 \mathrm{~s}$, and is cleared when the affected circuit is tripped at $t=1.06 \mathrm{~s}$; its effect on the system is presented in Fig. 4. This power system is well damped, with the damping ratio of all the eigenvalues being over $10 \%$, even when this line is tripped after the short circuit, as can be seen in Fig. 4 a. In the 100 MW scenario, the modes seem to be just slightly affected by the type of control of the PV plants, whereas in the $800 \mathrm{MW}$ scenario, more differences can be observed, with the SPC reducing the damping of one mode, which is nonetheless higher than $10 \%$.

The general response of the system in terms of voltage, frequency, and active power injection by the main synchronous generators for the line contingency is very similar for both controllers, which is expected given the similarities in the eigenvalues defining their dynamic response. Nevertheless, the response of the PV plants is determined by the type of controller, as shown in Fig. $4 \mathrm{~b}$, where the active powers generated by the studied PV plant are depicted in a plant-per-unit system. For the IPT controller, there is a short active power spike when the line is tripped, followed by a steady recovery of the pre-fault level in $1 \mathrm{~s}$. With the SPC, the plant exhibits the expected oscillatory behaviour of a synchronous machine, with the oscillations fading away in approximately $5 \mathrm{~s}$.

The impact of the line trip on the frequency of the system and the speed of synchronous machines can be seen in Fig. 4c, where the speed of Generator ANG2 at the Angamos plant is shown. In this figure, the frequency response is affected by the PV penetration level and the selected controller; the impact of the $100 \mathrm{MW}$ plant is limited, with the controller type having practically no effect on the system, but for the $800 \mathrm{MW}$ case, the controllers have a visible influence, especially during the first $2 \mathrm{~s}$ after the event, with the SPC limiting the acceleration of the system.

\subsection{Generator Contingency}

This event consists on the disconnection of Generator U15 at $\mathrm{t}=1 \mathrm{~s}$. This machine is connected at the Tocopilla plant and its active power reference is adapted for each scenario in such a way that it represents approximately 


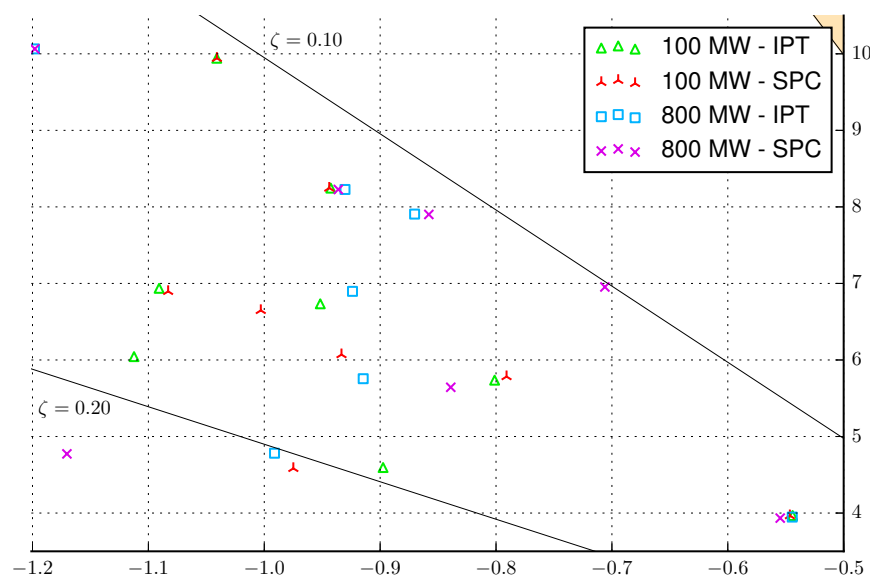

(a)

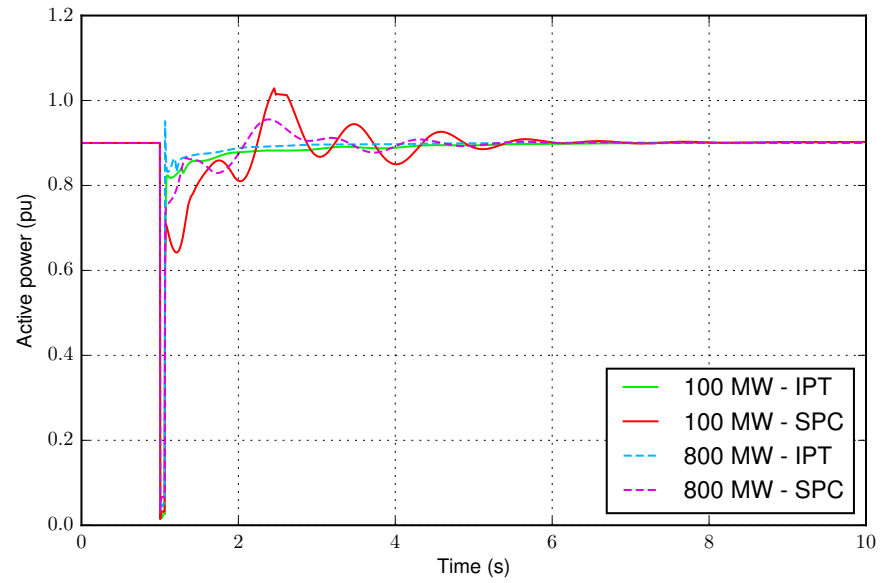

(b)

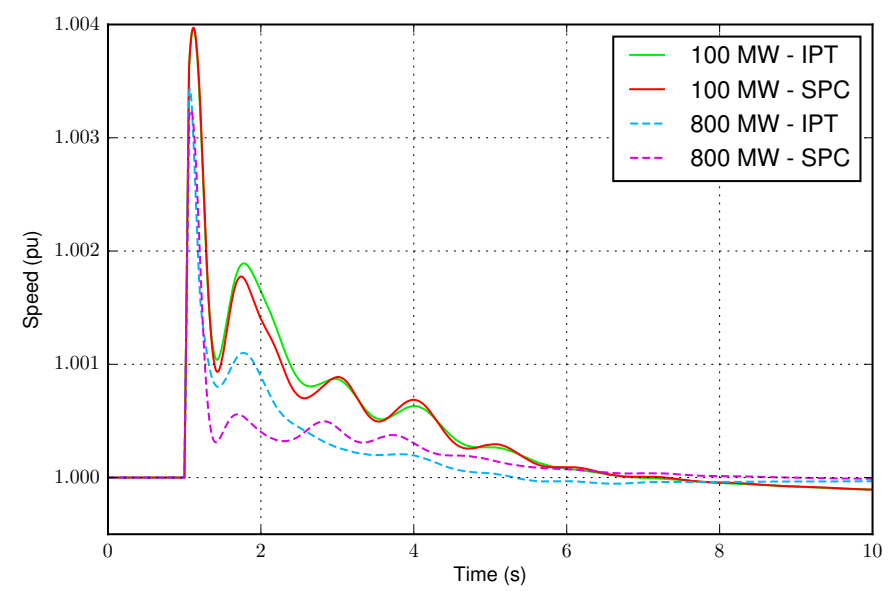

(c)

Fig. 4. Response of the power system of northern Chile to a contingency on Circuit 2 of the Crucero-Encuentro line for different scenarios: (a) eigenvalue plot, (b) Plant PVI active power in a plant-per-unit system, and (c) Generator ANG2 speed.

$4 \%$ of the total generation in both cases; hence, the severity of the disturbance is similar regardless of the considered PV penetration level.

The active power imbalance in the system has some effects on the response of the system as shown in Fig. 5. Thus, Fig. 5a depicts the active power response of the studied PV plant, on a plant-per-unit system, showing that the plant response depends fundamentally on the type of controller. When the SPC is employed, the response is initially faster due to the emulated inertia, and during the following 5 to 7 seconds, it has an oscillatory behaviour superimposed on the droop response to the frequency variation, as in the case of a synchronous machine. With the IPT controller, a steadier active power increase is seen, due to the droop response. Therefore, the inertia emulated by the SPC enables the PV plant to respond faster to the frequency event.

The PV plant active power response is related to the dc voltage of the equivalent converter, as can be 


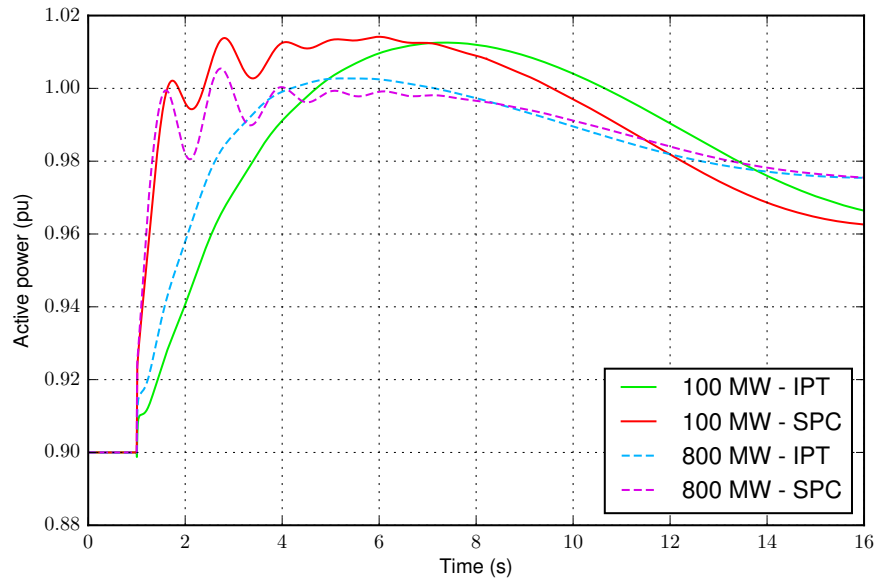

(a)

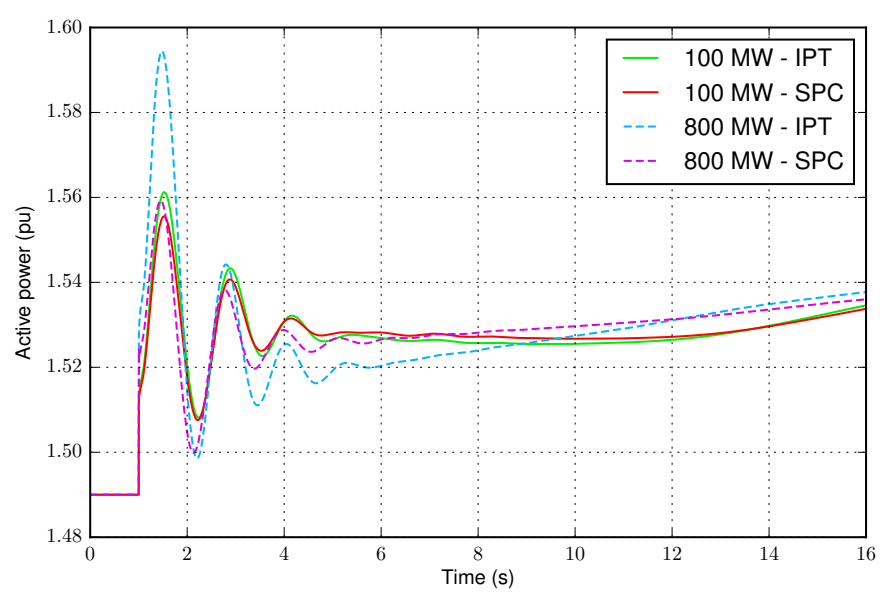

(c)

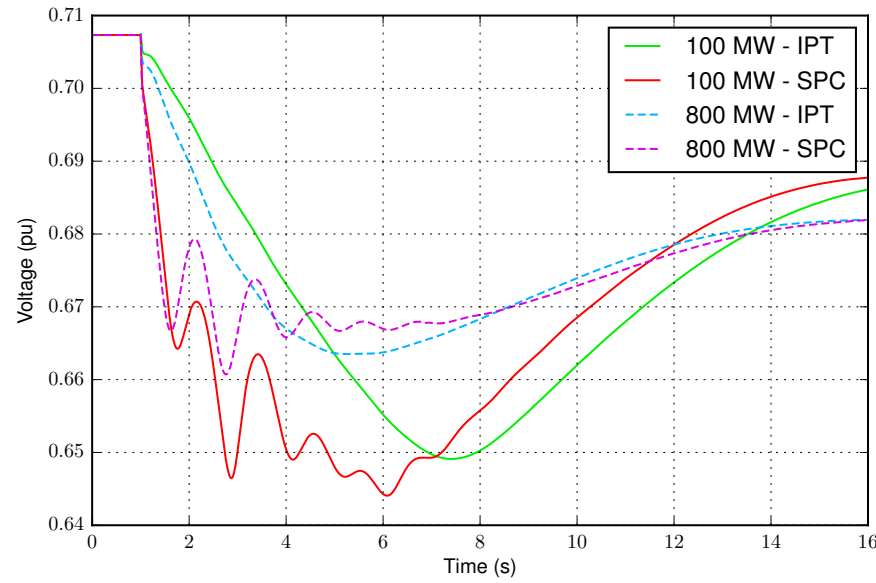

(b)

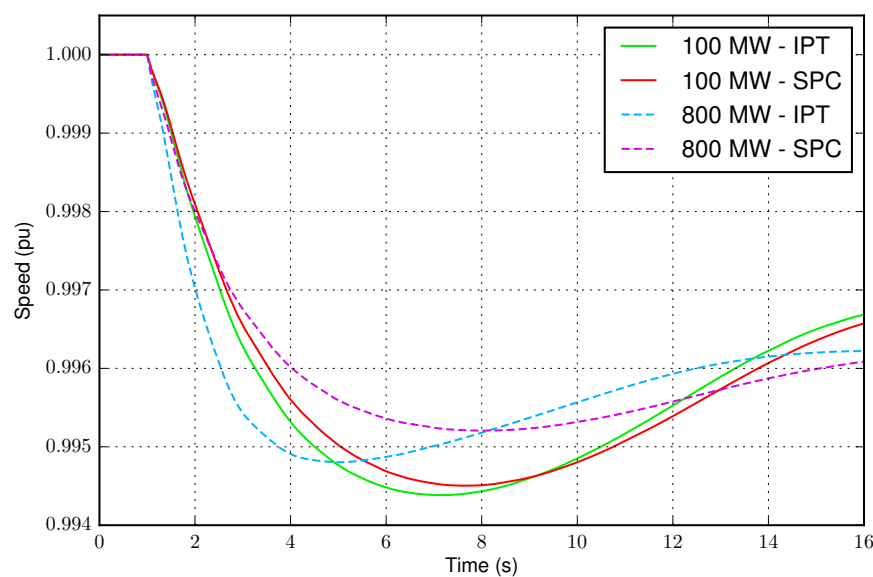

(d)

Fig. 5. Response of the power system of northern Chile to the disconnection of Generator U15 for different scenarios: (a) Plant PVI active power in a plant-per-unit system, (b) Plant PVI equivalent converter dc voltage, (c) Generator CTM1 active power, and (d) Generator ANG2 speed.

seen in Fig. 5b. As a result of the additional injection of active power, the dc capacitors discharge, and the voltage decreases. Furthermore, since the PV plant is operating in the stable region of the PV characteristics, this decrease of voltage results in a PV power increase, which rapidly balances the extra power injected into the grid and maintains the active power balance. Comparing the different scenarios, it is possible to see how, at the beginning of the transient, the faster response of the SPC results in a faster dc voltage drop, i.e., a faster energy release to compensate the frequency deviation, which is analogous to the inertial response of synchronous machines. In any case, the de voltage remains over the maximum power point voltage throughout the transient for all the scenarios, so the plant operates safely within the stable region of the PV curve.

The fast active power response of the PV plants when the SPC is employed has some beneficial effects for the power system. In particular, it alleviates the effort of the synchronous machines in the system, like unit CTM1 at the Mejillones plant, whose active power injection is shown in Fig. 5c. In the $100 \mathrm{MW}$ scenario, 
the use of the SPC by the PV plant contributes to a slight reduction of CTM1 active power oscillations with respect to the IPT controller. However, this contribution is more evident in the $800 \mathrm{MW}$ scenario, since the SPC keeps the oscillations in the same range as for the $100 \mathrm{MW}$ scenario, but the IPT results in appreciably larger oscillations, especially during the first swing of the machine.

Additionally, the SPC response has an influence on the system frequency, as can be inferred from the speed of Generator ANG2 shown in Fig. 5d. The system frequency is affected differently in each scenario, and the differences due to the controller type are more evident as the PV penetration increases. In the $100 \mathrm{MW}$ scenario, the influence of the PV plant controller on the system response is limited by the small relative size of the plant compared with the whole system, but the response induced by the SPC makes possible a slight reduction of the frequency slope and its maximum deviation. On the other hand, in the $800 \mathrm{MW}$ scenario, there are more visible effects; thus, the SPC contributes to a significant reduction in the rate of change of the frequency, which eventually results in a reduced maximum frequency deviation of $8 \%$, taking place $3 \mathrm{~s}$ later than in the case of the IPT controller.

\subsection{Load Contingency}

This third event is defined by the disconnection of several loads connected near the Crucero bus, which represent around $8 \%$ of total demand in all scenarios. Therefore, the active power balance is significantly affected, with the power system frequency increasing in this case, as expected. The response of the power system to this event, which takes place at $\mathrm{t}=1 \mathrm{~s}$, is shown in Fig. 6 .

The active power response of Plant PV1 for this event is shown in Fig. 6a, also on a plant-per-unit system. As in the case of the disconnection of the generator, the response is clearly dependent on the employed controller, and the SPC results in a faster reaction, with a sharp decrease of active power generation in order to compensate the loss of load. With the IPT, the active power reduction is slower, tracking the resulting frequency increase. The effects of the event on the equivalent converter dc voltage can be seen in Fig. $6 \mathrm{~b}$. In this case, the active power reduction charges the dc capacitors, increasing their voltage and thus reducing the power generated by the PV system. With the SPC, the plant absorbs more power at the beginning of the transient, thus opposing the disturbance. In all scenarios, the dc voltage increase is moderate and the PV system continues operating in its stable region.

The SPC response also brings benefits for the power system when a load is disconnected. On the one hand, the effort of the synchronous machines is reduced once again, especially for the $800 \mathrm{MW}$ scenario, 


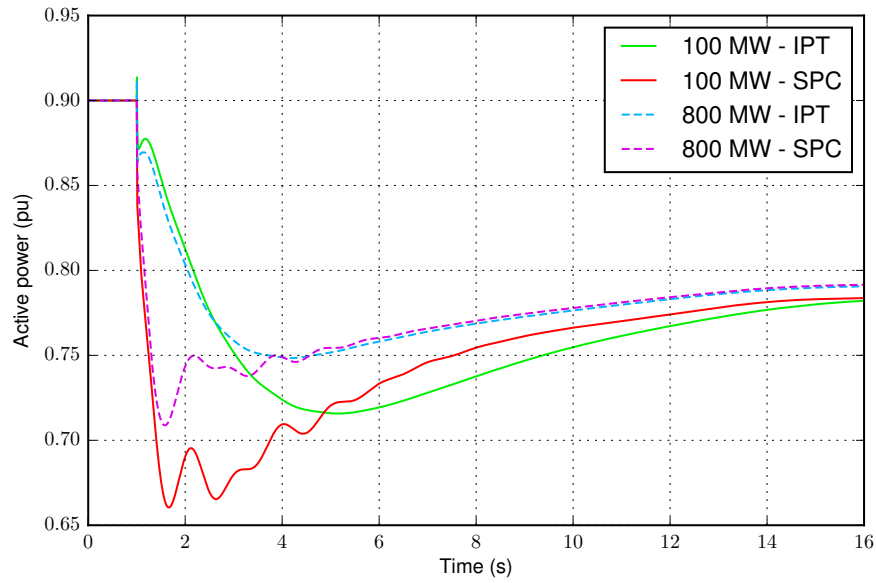

(a)

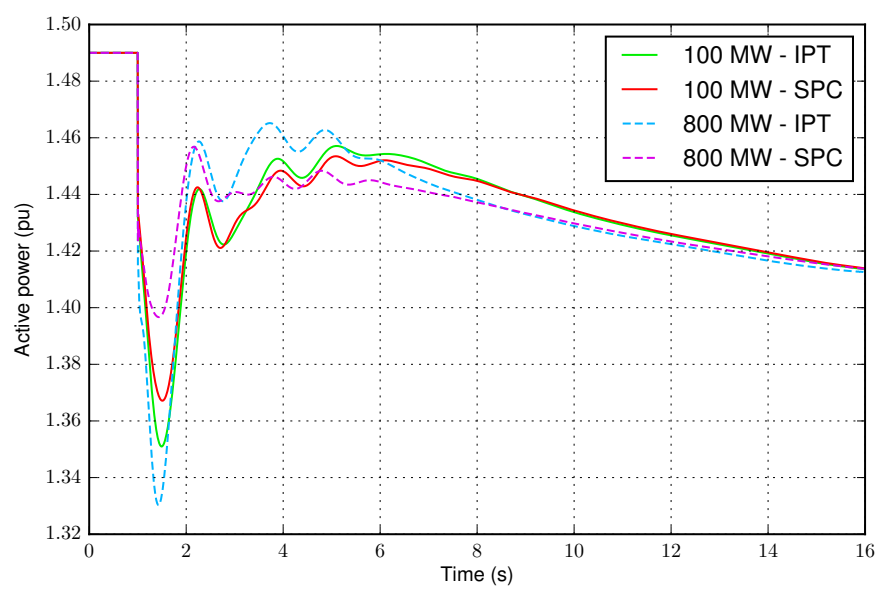

(c)

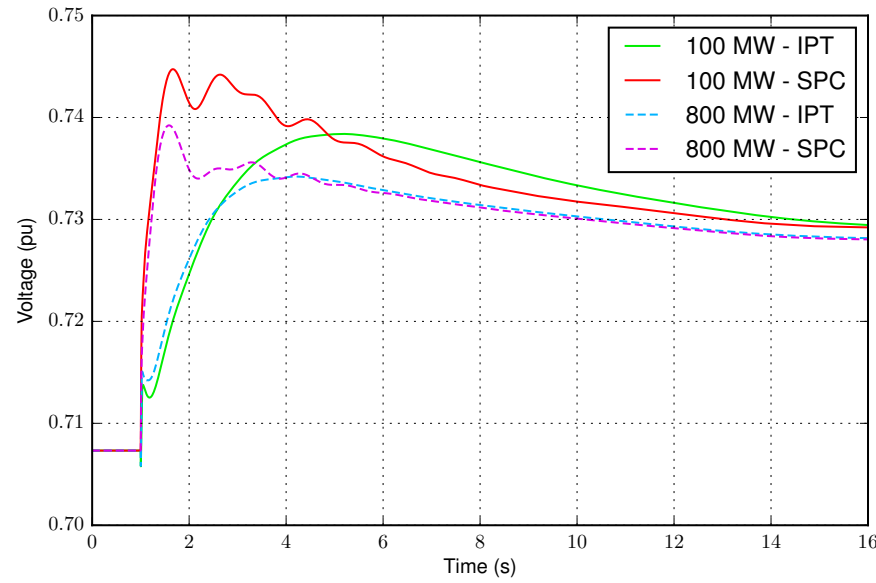

(b)

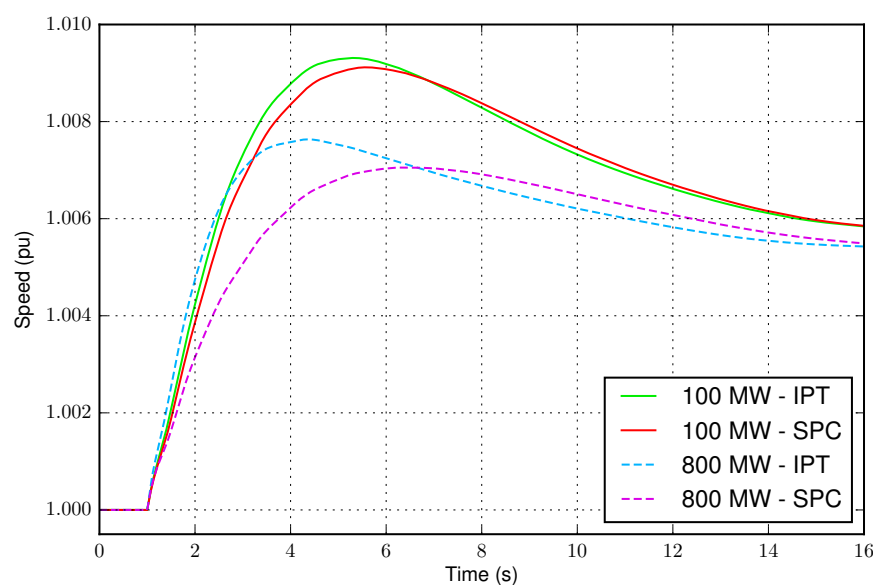

(d)

Fig. 6. Response of the power system of northern Chile to the disconnection of loads for different scenarios: (a) Plant PVI active power in a plant-per-unit system, (b) Plant PVI equivalent converter dc voltage, (c) Generator CTM1 active power, and (d) Generator ANG2 speed.

as can be seen in Fig. 6c for unit CTM1, which presents a significant reduction of oscillations when the SPC is employed. On the other hand, the additional inertia provided by the PV plants employing the SPC contributes decisively to limiting the rate of change of the frequency, and thus its maximum deviation. When the PV penetration increases, the effect on the maximum frequency deviation becomes evident, delaying the occurrence of the maximum for approximately $2 \mathrm{~s}$, and reducing its value around $9 \%$.

\section{Conclusion}

In this paper, the impact on a the Northern Chile power system of an actual large-scale PV plant employing power converters with the capability of behaving as virtual synchronous generators was analysed. In the presented studies, the PV plant was represented by an equivalent model that takes into account the central 
plant controller, the converter controller, and the characteristics of the dc side and the PV system, so that the limitations due to the solar resource can be taken into account. Using an SPC, the plant was shown to act in a grid-friendly manner, like a conventional synchronous machine. In order to evaluate the impact of this type of controller, it was compared against a conventional converter controller based on IPT.

The results for the studied power system prove that power plants formed by virtually synchronous power converters can contribute to the stability of power systems. The inertial response defined by the SPC allows the plant to react to power imbalances in the system, mitigating frequency transients by limiting both its rate of change and its maximum deviation, while it operates in the stable region of the PV curve. Additionally, this response also has a beneficial effect on the synchronous machines contributing to frequency regulation in the system, which experience less severe oscillations when the SPC is enabled. As demonstrated in the paper, the beneficial effects of the SPC are more visible as the solar penetration grows, enabling the integration of renewable generators without reducing the effective inertia of the system.

\section{Acknowledgments}

This work has been partially supported by the Spanish Ministry of Science and Innovation under the project ENE2014-60228-R, the Fundación Bancaria la Caixa, and an NSERC-Canada Discovery Grant.

Any opinions, findings and conclusions or recommendations expressed in this material are those of the authors and do not necessarily reflect those of the host institutions or funders.

\section{References}

[1] Observ'ER, 'The state of renewable energies in Europe. Edition 2014' (2014), http://www.energiesrenouvelables.org/observ-er/stat_baro/barobilan/barobilan14-gb.pdf, accessed April 2017

[2] European Commission, 'A policy framework for climate and energy in the period from 2020 to 2030' (2014), http://eur-lex.europa.eu/legal-content/EN/TXT/PDF/?uri=CELEX:52014DC0015\&from=EN, accessed April 2017

[3] U.S. Energy Information Administration, 'Electric power monthly with data for December 2016' (2017), http://www.eia.gov/electricity/monthly/current_year/february2017.pdf, accesed April 2017

[4] Durkay, J., 'State renewable portfolio standards and goals', http://www.ncsl.org/research/energy/renew able-portfolio-standards.aspx, accessed April 2017 
[5] Adefarati, T., Bansal, R. C.: 'Integration of renewable distributed generators into the distribution system: A review', IET Renewable Power Generation, 2016, 10, (7), pp. 873-884

[6] Armendariz, M., Babazadeh, D., Brodén, D., Nordström, L.: 'Strategies to improve the voltage quality in active low-voltage distribution networks using DSO's assets', IET Generation, Transmission \& Distribution, 2017, 11, (1), pp. 73-81

[7] Yan, R., Saha, T. K., Meredith, P., Ananth, A., Hossain, M. I.: 'Megawatt-scale solar variability study: An experience from a 1.2 MWp photovoltaic system in Australia over three years', IET Renewable Power Generation, 2016, 10, (8), pp. 1229-1236

[8] Watson, J. D., Watson, N. R., Santos-Martin, D., Wood, A. R., Lemon, S., Miller, A. J. V.: 'Impact of solar photovoltaics on the low-voltage distribution network in New Zealand', IET Generation, Transmission \& Distribution, 2016, 10, (1), pp. 1-9

[9] Edrah, M., Lo, K. L., Anaya-Lara, O.: 'Impacts of high penetration of DFIG wind turbines on rotor angle stability of power systems', IEEE Transactions on Sustainable Energy, 2015, 6, (3), pp. 759-766

[10] Yagami, M., Kimura, N., Tsuchimoto, M., Tamura, J.: 'Power system transient stability analysis in the case of high-penetration photovoltaics'. IEEE PowerTech, Grenoble, France, June 2013, pp. 1-6

[11] Martín-Martínez, S., Gómez-Lázaro, E., Molina-Garcia, A., Honrubia-Escribano, A.: 'Impact of wind power curtailments on the Spanish power system operation'. IEEE PES General Meeting, National Harbor, Maryland USA, July 2014, pp. 1-5

[12] Fernandes, C., Frías, P., Olmos, L.: 'Expanding interconnection capacity to integrate intermittent generation in the Iberian Peninsula', IET Renewable Power Generation, 2013, 7, (1), pp. 45-54

[13] Rather, Z. H., Chen, Z., Thogersen, P.: 'Impact of wind energy integration on reactive power reserve and its smart solution: A Danish power system case study'. IEEE International Conference on Power System Technology (POWERCON), Auckland, New Zealand, October 2012, pp. 1-6

[14] Makarov, Y. V., Loutan, C., Ma, J., de Mello, P.: 'Operational impacts of wind generation on California power systems', IEEE Transactions on Power Systems, 2009, 24, (2), pp. 1039-1050

[15] Helander, A., Holttinen, H., Paatero, J.: 'Impact of wind power on the power system imbalances in Finland', IET Renewable Power Generation, 2010, 4, (1), pp. 75-84 
[16] Rodriguez, J. M., Fernandez, J. L., Beato, D., Iturbe, R., Usaola, J., Ledesma, P., Wilhelmi, J. R.: 'Incidence on power system dynamics of high penetration of fixed speed and doubly fed wind energy systems: Study of the Spanish case', IEEE Transactions on Power Systems, 2002, 17, (4), pp. 1089-1095

[17] Tamimi, B., Cañizares, C., Bhattacharya, K.: 'System stability impact of large-scale and distributed solar photovoltaic generation: The case of Ontario, Canada', IEEE Transactions on Sustainable Energy, 2013, 4, (3), pp. 680-688

[18] Wang, Y., Silva, V., Lopez-Botet-Zulueta, M., 'Impact of high penetration of variable renewable generation on frequency dynamics in the continental Europe interconnected system', IET Renewable Power Generation, 2016, 10, (1), pp. 10-16

[19] Eftekharnejad, S., Vittal, V., Heydt, G. T., Keel, B., Loehr, J.: 'Small signal stability assessment of power systems with increased penetration of photovoltaic generation: A case study', IEEE Transactions on Sustainable Energy, 2013, 4, (4), pp. 960-967

[20] Kim, E. H., Kim, J. H., Kim, S. H., Choi, J., Lee, K. Y., Kim, H. C., 'Impact analysis of wind farms in the Jeju Island power system', IEEE Systems Journal, 2012, 6, (1), pp. 134-139

[21] Delille, G., Francois, B., Malarange, G.: 'Dynamic frequency control support by energy storage to reduce the impact of wind and solar generation on isolated power system's inertia', IEEE Transactions on Sustainable Energy, 2012, 3, (4), pp. 931-939

[22] Han, C., Huang, A. Q., Baran, M. E., Bhattacharya, S., Litzenberger, W., Anderson, L., Johnson, A. L., Edris, A. A.: 'STATCOM impact study on the integration of a large wind farm into a weak loop power system', IEEE Transactions on Energy Conversion, 2008, 23, (1), pp. 226-233

[23] Shah, R., Mithulananthan, N., Lee, K. Y., 'Large-scale PV plant with a robust controller considering power oscillation damping', IEEE Transactions on Energy Conversion, 2013, 28, (1), pp. 106-116

[24] Korai A. W., Erlich, I.: 'Frequency dependent voltage control by DER units to improve power system frequency stability'. IEEE PowerTech, Eindhoven, Netherlands, June 2015, pp. 1-6

[25] Miller, N., Clark, K., Shao, M.: 'Frequency responsive wind plant controls: Impacts on grid performance'. IEEE PES General Meeting, Detroit, Michigan USA, July 2011, pp. 1-8

[26] Bevrani, H., Ise, T., Miura, Y.: 'Virtual synchronous generators: A survey and new perspectives', Electrical Power and Energy Systems, 2014, 54, pp. 244-254 
[27] Van Wesenbeeck, M. P. N., De Haan, S. W. H., Varela, P., Visscher, K., 'Grid tied converter with virtual kinetic storage'. IEEE PowerTech, Bucharest, Romania, June 2009, pp. 1-7

[28] Torres M., Lopes, L. A. C.: 'Virtual synchronous generator control in autonomous wind-diesel power systems’. IEEE Electrical Power Energy Conference (EPEC), Montreal, Canada, October 2009, pp. 1-6

[29] Chen, Y., Hesse, R., Turschner, D., Beck, H.-P.: 'Improving the grid power quality using virtual synchronous machines'. IEEE International Power Engineering, Energy and Electrical Drives (POWERENG), Torremolinos, Spain, May 2011, pp. 1-6

[30] Shintai, T., Miura, Y., Ise, T.: 'Oscillation damping of a distributed generator using a virtual synchronous generator', IEEE Transactions on Power Delivery, 2014, 29, (2), pp. 668-676

[31] Tamrakar, U., Galipeau, D., Tonkoski, R., Tamrakar, I.: 'Improving transient stability of photovoltaichydro microgrids using virtual synchronous machines'. IEEE PowerTech, Eindhoven, Netherlands, June 2015, pp. 1-6

[32] Zhang, W., Remon, D., Rodriguez, P., 'Frequency support characteristics of grid-interactive power converters based on the synchronous power controller', IET Renewable Power Generation, October 2016, http://digital-library.theiet.org/content/journals/10.1049/iet-rpg.2016.0557

[33] Remon, D., Cantarellas, A. M., Mauricio, J. M., Rodriguez, P.: 'Power system stability analysis under increasing penetration of photovoltaic power plants with synchronous power controllers,' IET Renewable Power Generation, March 2017, http://digital-library.theiet.org/content/journals/10.1049/ietrpg.2016.0904

[34] Rodriguez, P., Candela, I., Luna, A.: 'Control of PV generation systems using the synchronous power controller'. IEEE Energy Conversion Congress and Exposition (ECCE), Denver, Colorado USA, Sept 2013, pp. 993-998

[35] Rodriguez Cortés, P., Candela García, J. I., Rocabert Delgado, J., Teodorescu, R.: 'Synchronous power controller for a generating system based on static power converters'. International Patent WO 2012/117131 A1, September 2012, Priority date: February 18, 2011, Licensed by: Abengoa, S.A.

[36] Teodorescu, R., Liserre, M., and Rodriguez, P.: 'Grid Converters for Photovoltaic and Wind Power Systems' (Wiley, Chichester, 2011) 
[37] Remon, D., Cantarellas, A. M., Rodriguez, P.: 'Equivalent model of large-scale synchronous photovoltaic power plants', IEEE Transactions on Industry Applications, 2016, 52, (6), pp. 5029-5040

[38] Babu, B. C., Gurjar, S.: 'A novel simplified two-diode model of photovoltaic (PV) module', IEEE Journal of Photovoltaics, 2014, 4, (4), pp. 1156-1161

[39] 'Coordinador Eléctrico Nacional - SING', http://cdec2.cdec-sing.cl/pls/portal/cdec.pck_web_coord_elec. sp_pagina?p_id=4, accessed April 2017

[40] Coordinador Eléctrico Nacional - SING, 'Sistema Interconectado Norte Grande - Esquema Geográfico’ (2016), http://cdec2.cdec-sing.cl/pls/portal/cdec.pck_web_coord_elec.sp_pagina?p_palabra=mapa+sing \&pid=1, accessed April 2017

[41] 'Coordinador Eléctrico Nacional - SING. Base de datos del SING', http://cdec2.cdec-sing.cl/pls/portal /cdec.pck_web_coord_elec.sp_pagina?p_id=1087, accessed April 2017 